\title{
Squeezing or cuddling? The impact of economic crises on management control and stakeholder management
}

\author{
Johannes A. Asel • Arthur Posch • \\ Gerhard Speckbacher
}

Received: 3 September 2010/Accepted: 29 September 2010/Published online: 19 October 2010

(C) Springer-Verlag 2010

\begin{abstract}
This paper analyzes the effects of economic crises on firms' use of management control mechanisms and on their management of stakeholder relations. Moreover, the association between stakeholder management and management control system use is analyzed. In the wake of the economic crisis of 2008/2009, many firms were faced with severe threats that called for immediate short-term action to ensure firm survival. However, short-term action like massive cost-cutting and cash generation often are blamed for going at the expense of long-term health as key stakeholder relations may be irreversibly harmed. Hence, three interrelated questions are addressed theoretically and empirically: First, we analyze the impact of the recent economic crisis on firms' control strategies. More specifically, we investigate whether a high crisis impact on firms is associated with a shortening of reporting cycles, a more interactive use of control-relevant information, restriction of employee autonomy and a focus on liquidity and cost-cutting. Second, we examine from the viewpoint of stakeholder theory how firms can make use of active stakeholder management for crisis management. Third, we explore whether firms can take short-term measures for ensuring liquidity and cutting costs and at the same time pursue a stakeholder strategy aiming at the long-term survival of the firm. Using survey data from 204 major Austrian corporations, we provide evidence that firms significantly adjusted their control systems as a response to the economic crisis. Our data do not indicate an immanent contradiction between a "short-term finance focus" and the pursuit of a sustainable stakeholder strategy.
\end{abstract}

J. A. Asel $(\bowtie) \cdot$ A. Posch · G. Speckbacher Institute for Strategic Management and Management Control, Vienna University of Economics and Business, Nordbergstrasse 15, 1090 Vienna, Austria e-mail: johannes.asel@wu.ac.at

A. Posch

e-mail: arthur.posch@wu.ac.at

G. Speckbacher

e-mail: gerhard.speckbacher@wu.ac.at 
Keywords Crisis $\cdot$ Management control $\cdot$ Stakeholder management $\cdot$ Management accounting

\section{JEL Classification M49-Other}

\section{Introduction}

In the wake of the economic crisis of 2008/2009, many firms were faced with severe threats that called for immediate action to ensure firm survival. When choosing the measures to cope with this crisis situation, responsible decision makers were confronted with the challenge to manage the trade-off between the benefits and costs of short-term crisis reactions (Rhodes and Stelter 2009). On the one hand, shortterm action like massive cost-cutting, cash generation, shorter reporting cycles, increased employee monitoring and tight budget control seemed necessary to cope with a decline in orders and revenues and to ensure an appropriate and wellcoordinated response to changed environmental conditions. On the other hand, such short-term measures might damage the long-term growth potential and go at the expense of the long-term health of the firm as key stakeholder relations may be irreversibly harmed.

Hence, the recent economic crisis has intensified the debate on whether and how it is possible to harmonize shareholders' demand for profitability (also in the short run) with the concerns of other stakeholders, including society and the environment (Sundin et al. 2010). Although the importance of incorporating stakeholder concerns into management accounting systems has been acknowledged (e.g. Nixon and Burns 2005), there seems to be relatively little progress on how this can be accomplished (Malmi and Granlund 2009). Existing research in management accounting has mainly dealt with the measurement of stakeholder-related information. Accountability aspects of stakeholder management like environmental and social reports, sustainability reports and international standards, such as the sustainability reporting guidelines, have been discussed. Performance measurement systems like the balanced scorecard (BSC) have extended the traditional financial focus of performance management systems to also include nonfinancial and stakeholder related measures (Perrini and Tencati 2006; Speckbacher et al. 2003).

However, there is a lack of research in management accounting that goes beyond performance measurement and accountability aspects of stakeholder management and, in particular, there is a lack of research on how stakeholder management systems relate to management control systems and how both systems might be integrated.

Management control can be defined as the set of mechanisms designed and implemented by top management in order to influence and control the behaviour of subordinate managers and employees to better attain organizational goals (e.g. Merchant and Van der Stede 2007; Malmi and Brown 2008). As far as organizational goals are not restricted to shareholder interests but also include stakeholder concerns, management control systems obviously need to take account of such stakeholders. Even firms that subscribe to shareholder value maximization 
as their ultimate goal need to actively manage stakeholder relations, as the generation of shareholder value depends on the contribution of key stakeholders like customers, employees and suppliers (e.g. Freeman and Gilbert 1987; Jones 1995; Mitchell et al. 1997). However, stakeholder relationships are not only the basis for firm value generation, they are also important for managing the distribution of value and the allocation of risks. The explicit and implicit contracts that a firm negotiates with its stakeholders specify what the firm expects from its stakeholders (defining each stakeholder's contribution to value generation) and what each stakeholder can expect from the firm in return for his/her cooperation (Atkinson et al. 1997). Since important parts of these contractual relationships are not written down in explicit form, this leaves considerable scope for firms deciding on the degree to which stakeholder expectations are fulfilled. In particular, in times of financial pressure and unfavourable environmental conditions, a firm's management has the opportunity to improve short-term financial results at the expense of stakeholders' implicit claims and to shift financial risks from shareholders to other stakeholders. While there are obvious positive short-term effects in terms of cost reduction and cash generation, the negative long-term effects are often less visible but not necessarily less important (Cornell and Shapiro 1987; Speckbacher and Wentges 2010).

Theoretical insights and empirical evidence on how management can deal with this trade-off between short-term benefits and long-term costs of such measures in times of high pressure due to economic crises seem to be missing. In particular, extant research lacks insights into how companies adapt their management control systems as a response to crisis situations (Hopwood 2009). More generally, there is scant evidence on the interrelationship between stakeholder management and management controls (Chenhall 2003). By providing decision-relevant information and guiding employee behavior with regards to the management of stakeholder relations, management control systems obviously play an important role for managing stakeholder relations, particularly in crisis situations.

In this paper three interrelated questions are analyzed theoretically and empirically: First, we analyze the impact of the recent economic crisis on firms' control strategies. Building on extant literature on firms' reactions in crisis situations, we analyze whether firms that were severely affected by the economic crisis seek for an increased frequency of control-relevant information, focus on the interactive use of control-relevant information, restrict employee autonomy and focus on liquidity and cost-cutting. Second, we examine from the perspective of stakeholder theory how firms can cope with (external) economic crises using active stakeholder management to ensure firm survival and continued value generation. Third, we explore whether certain "control strategies" are associated with certain "stakeholder policies". In particular, we analyze whether firms' focus on liquidity and cost-cutting in times of crisis is compatible with a sustainable stakeholder strategy or not.

For our empirical analysis we use survey data from 204 major Austrian corporations. Our empirical results indicate that in times of crisis firms significantly adjust their management control mechanisms in the predicted way but, at the same time, focus on sustainable relations with both internal and external stakeholders. 
Most interestingly, there seems to be no contradiction between the emphasis placed on control mechanisms and the pursuit of a sustainable stakeholder strategy.

\section{Crisis reactions from a management control perspective}

Effective crisis management hinges on precise and quick implementation of decisions (Smart and Vertinsky 1977). Increasing the frequency of data reporting helps firms to react faster and more flexibly to new situations and circumstances triggered by external crisis (Davila et al. 2009). From an informational perspective, Galbraith (1973) describes management controls as a means to bridge the gap between information needs and actually available information for decision-making. Crisis situations are characterized by immediate and unexpected changes of the environment (Pearson and Clair 1998) and, therefore, quick feedback to decision makers on changes in the environment becomes vital to enable them to take corrective action if necessary (Smart and Vertinsky 1977).

Lower-level employees are often closer to the market and shortened reporting cycles can ensure that top management can make use of up-to-date information that is available to subordinated organizational units and lower-level employees. The increased importance of the current availability of relevant information in crisis situations is underscored also by Ezzamel and Bourn (1990). Thus, we expect firms that are severely impacted by economic crises to have an increased need for up-todate data and shortening their reporting cycles.

$\mathbf{H}_{1 \mathbf{a}}$ Crisis impact is positively related to the shortening of reporting cycles.

Occurrence of an external crisis can not only be expected to have an impact on the need for up-to-date data but also on data usage and interpretation. Accounting data can be used in different ways, as is pointed out by several authors. Simons (1995) distinguishes two ways of how to use accounting information: interactively and diagnostically. Whereas a diagnostic use of accounting data is characterized by the cybernetic control principle of monitoring results, the interactive use of data is a future-orientated way of interpreting and discussing accounting information. Assumptions are frequently challenged and developments in the external environment and within the organization are continually monitored and coordinated. These discussions are intended to not only improve coordination but also informationsharing among employees in different departments, as well as individual and organizational learning.

Since crisis situations are typically characterized by an increased need for information-sharing and coordination across different hierarchy levels as well as across organizational units (Pearson and Clair 1998), it can be expected that the demand for interactive use of accounting data is higher in times of crisis. Moreover, when environmental conditions change rapidly due to the occurrence of an external crisis, fast organizational learning about adequate reactions to changed conditions becomes vital.

By intensifying deviation analysis, encouraging discussion about deviations and by striving for increased communication among organizational units, firms can 
improve immediate mutual adjustment among organizational units, improve swift coordination in face of a fast-changing environment and improve individual and organizational learning (Simons 1995). As a consequence, we expect firms that are severely impacted by economic crises to make more interactive use of controlrelevant information.

$\mathbf{H}_{1 \mathrm{~b}}$ Crisis impact is positively related to interactive use of control-relevant information.

Besides the proposed implications on the demand for information and on information usage, crisis situations can also influence the extent to which decision rights are delegated.

The restriction of employee autonomy is one of the most direct forms of ensuring that employees act in the best interest of the organization (Merchant and Van der Stede 2007). High unpredictability of the environment in times of crisis makes the measurement of the outcomes of delegated tasks particularly difficult. This provides more room for opportunistic employee behavior (Merchant 1990). Moreover, agents who are not able to achieve targets because of unfavorable environmental conditions may be de-motivated. In such situations, agents may also feel inclined to take excessive risks in order to reach their targets despite unfavorable conditions. Hence, during crisis situations, there is a tendency to place constraints on the behavior of employees and to restrict their autonomy (Hermann 1963).

$\mathbf{H}_{1 \mathrm{c}}$ Crisis impact is positively related to employee autonomy restriction.

Crisis situations are typically characterized by a high pressure on decision-makers and a severe threat to firm survival (Pearson and Clair 1998). Most importantly, in times of crisis firm survival is threatened by financial distress and when revenues become more uncertain, preserving liquidity and radically adjusting cost levels to changing demand levels becomes crucial (Hopwood 2009). According to Müller (1985), effective crisis management needs to put a focus on cost-cutting, budgetcutting and liquidity protection. In a similar vein, Rhodes and Stelter (2009) point out the protection of financial fundamentals as an effective strategy for reducing a firm's exposure to negative crisis effects. Since incentive systems are not only important in motivating employees to making a greater effort but also quite effective for communicating "what really counts" (e.g. Merchant and Van der Stede 2007), the increased focus on liquidity and cash-related goals, as well as on cost-cutting, may also be reflected in an increased use of cash and cost-related measures for incentive compensation (Gilson and Vetsuypens 1993; Ittner et al. 1997). Hence, we expect firms that are severely impacted by economic crises to focus on liquidity and cost-cutting.

$\mathbf{H}_{1 d}$ Crisis impact is positively related to a focus on liquidity and cost-cutting.

\section{A stakeholder perspective on crisis management}

It has been argued that an active management of stakeholder relations is especially important during times of crisis (Pearson and Mitroff 1993; Pearson and Clair 
1998). Crisis management is even characterized as a "systematic attempt by organizational members with external stakeholders to avert crises or to effectively manage those that do occur" (Pearson and Clair 1998).

According to stakeholder theory, stakeholder relationships are the basis for value generation and the explicit and implicit contractual relationships of the firm with its stakeholders specify what the firm expects from its stakeholders and what stakeholders expect from the firm (e.g. Freeman and Gilbert 1987; Jones 1995; Mitchell et al. 1997; Atkinson et al. 1997). In times of crisis these relationships are severely affected and continued support of stakeholders has to be ensured to warrant firm survival. This will require considerate renegotiations of explicit and implicit contracts focussing on the continued balance between the contributions and benefits for each stakeholder to ensure long-term cooperation. Increased communication with stakeholders can help to preserve trust even when the terms of cooperation need to be adjusted and stakeholders have to bear part of the negative effects of crises. Ritchie (2004) emphasizes the necessity of understanding the needs of and cooperating with both internal (employees) and external (e.g. customers, providers of finance capital, suppliers) stakeholders to manage crisis situations.

Pearson and Mitroff (1993) have developed a framework for effective crisis management which describes stakeholder management as a major component. The role of stakeholders during crises is described as twofold: Firstly, they might help an organization to cope with negative crisis effects and, secondly, in doing so they themselves are negatively affected. In order to reap the benefits of stakeholder support during crises it is of vital importance to disseminate information quickly, accurately, directly and candidly to critical stakeholders (Pearson and Clair 1998). Similarly, Ulmer (2001) stresses the importance of intense stakeholder relationships to resolve organizational crises.

Taken together, from the viewpoint of stakeholder theory firms that are severely impacted by an economic crisis can be expected to intensify communication and coordinated action with both internal and external stakeholders to find a sustainable way of sharing risks and other burdens caused by the changed environmental conditions during an economic crisis.

$\mathbf{H}_{2}$ Crisis impact is positively associated with emphasis placed on sustainable relations with external stakeholders and with employees.

\section{Short-term finance focus and the long-term health of the firm in times of crisis}

While stakeholder theory points out the need of a long-term oriented stakeholder management during crisis situations, it seems questionable whether such long-term orientation is in fact compatible with the pressure on firms to focus on liquidity and to cut costs in crisis situations. When management control focuses on easily quantifiable financial measures in the face of a crisis, the multidimensional nature of performance may be neglected. There may be a tendency of over-quantification and thus dimensions that are usually difficult to measure, such as the sustainability of 
stakeholder relations, are neglected or at least underrepresented in the controlling process (Merchant and Van der Stede 2007). The well-known adage "What you measure is what you get" indicates the problem that employees tend to focus on issues that get measured and rewarded even if they know that their actions are detrimental to the organization (Kaplan and Norton 1996).

Another problem of management control deals with gamesmanship. As Merchant and Van der Stede (2007) point out, employees often take actions that improve their own performance at the expense of long-term stakeholder relations of the organization. A typical example would be the dysfunctional effects of incentive systems. In an attempt to reach his quarterly sales target, a salesman might be inclined to sell a lower quality product to customers. In the short run, this results in a benefit for the salesman and the company; however, in the long run the customer relation might be put at risk or even irreversibly harmed. This example illustrates that there might be a trade-off between the emphasis placed on short-term financial measures and the pursuit of a sustainable stakeholder strategy (long-term customer relation).

From the viewpoint of stakeholder theory, the implicit nature of contractual relationships between the firm and its stakeholders bears the potential for firms to improve short-term financial results at the expense of stakeholders' implicit claims in times of financial pressure and unfavourable environmental conditions. By such active (short-term) management of stakeholder relations, firm risk may be shifted from shareholders to stakeholders and such a shift may cause severe negative longterm effects on organizational capital (Cornell and Shapiro 1987; Speckbacher and Wentges 2010).

On the other hand, also financial measures provide relevant information that might enable organizations to make decisions for ensuring the long-term survival of the firm and to learn about how the pressures and burdens arising from external crises can be fairly divided among all stakeholders, eventually enabling win-winsituations. An example would be to grant more favorable terms of payment to key customers in times of crisis in order not to accelerate their insolvency. Just the same, employees may accept lower effective wages in order to cut production costs and prevent layoffs in the longer run. As this indulgence towards external stakeholders can cause higher short-term risk for the firm and financial effects need to be closely monitored, it might be sensible to even increase the monitoring of financial effects in order to collect and provide current decision-relevant information that helps to manage the stakeholder-related risks appropriately.

Hence, stakeholder theory seems to suggest that a higher focus on cash management and cost-cutting needs to be accompanied by intensified stakeholder management activities, including intensified communication and cooperative action. At the same time, stakeholder theory points at possible conflicts between short-term financial goals and long-term sustainability of stakeholder relations. When the pressure on firms for short-term financial results is particularly high, then such firms might prefer to concentrate on short-term action at the expense of long-term stakeholder management.

Moreover, in times of external shocks, it is quite unlikely that firms immediately adjust activities "optimally" to changed contingencies. Ferreira and Otley (2010) 


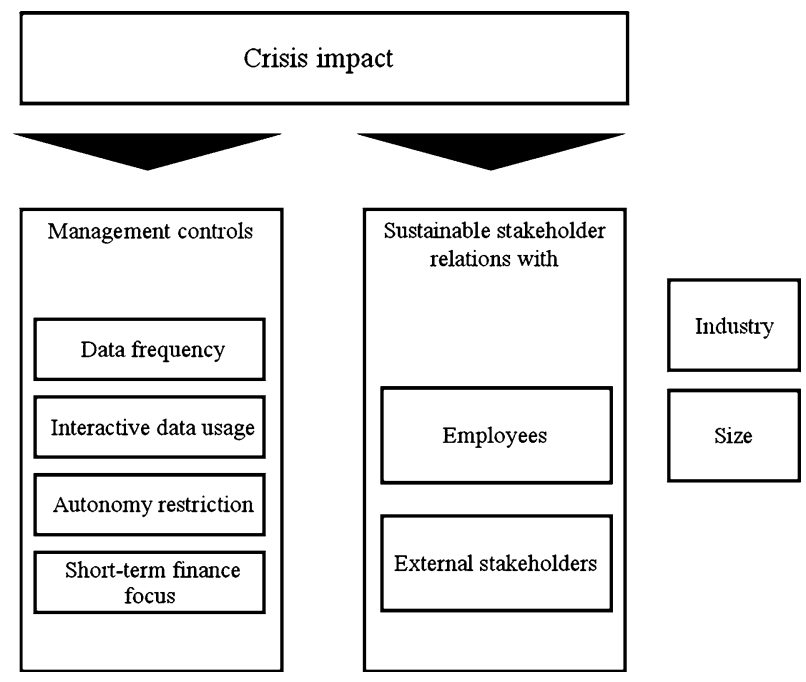

Fig. 1 Conceptual model

make the important point that there may be good reason why there is often no optimum fit between firms' choices of management control systems and the particular contingencies, at least when contingencies change rapidly. Therefore, we chose to explore empirically whether firms in fact take short-term measures for ensuring liquidity and cutting costs and at the same time pursue a stakeholder strategy aiming at the long-term survival of the firm. Figure 1 displays the conceptual model for this paper and summarizes the hypotheses.

\section{Research design}

\subsection{Sample}

The sample for this study is based on the 700 largest Austrian companies by revenue according to the AMADEUS database. Financial institutions as well as companies with less than 30 employees were excluded from the population, which reduced the sample size to 678 companies. The reasons for the exclusion of financial institutions are twofold. First, we addressed CFOs as target persons for our survey. The role of CFOs in financial institutions, however, is not comparable to other industries. Second, the inclusion of the financial industry would have led to a hardly controllable time-lag problem. The finance industry had been affected by the current crisis several months before the other industries and this would have reduced the comparability and subsequently the validity of our findings.

In line with previous surveys (e.g. Widener 2007), we addressed CFOs as target persons for our online survey as they are knowledgeable about the firm's control systems (Widener 2007). Initial contact with the 678 CFOs was established through the 'Österreichische Controller-Institut', which served as a co-sponsoring 
Table 1 Descriptive statistics for the survey respondents $(n=204)$

\begin{tabular}{lcccc}
\hline Sector & $\begin{array}{l}\text { Number } \\
\text { of firms }\end{array}$ & Percent & $\begin{array}{l}\text { Median turnover } \\
\text { (in million euro) }\end{array}$ & $\begin{array}{l}\text { Median } \\
\text { employees }\end{array}$ \\
\hline Production & 87 & 42.6 & 360 & 1,200 \\
Trade & 63 & 30.9 & 260 & 480 \\
Services & 35 & 17.2 & 600 & 2,360 \\
Other & 19 & 9.3 & 240 & 700 \\
Total & 204 & 100.0 & 332.5 & 940 \\
\hline
\end{tabular}

organization of this research project. Data collection for this paper was based on the online tool 2ask (www.2ask.at). The questionnaire was available in both, German and English. One and two weeks after the initial invitation email, reminder mails were sent to the non-respondents. Moreover, follow-up calls were made to further increase the number of respondents. This process resulted in a total of 204 responses received, which amounts to a response rate of $30.1 \%$. In comparison with other similar studies and in light of the challenging timing of the survey, this response rate seems to be quite satisfactory.

As Table 1 points out, the majority of respondents are CFOs of companies in the production sector (ca. 43\%). Approximately one-third of the survey participants were from the trade sector while $17 \%$ were from the service sector. The remainder of the responding companies did belong to other sectors. The median turnover of all companies having returned the survey amounted to 332.5 million euro, while the median number of employees was 940 .

On average, the participating CFOs had been in their current position for 6.5 years. Moreover, the vast majority of CFOs proved to be male (92\%) and reported to be responsible for the risk management agenda of their respective organizations $(83 \%)$. The average time to complete the survey was about $35 \mathrm{~min}$.

\subsection{Survey design}

Before the questionnaire was compiled, 28 qualitative interviews of about an hour were conducted with representatives of major finance and management accounting departments of major Austrian companies. The insights gained from this process helped to get a better understanding of the impact of the crisis on companies and the issues at stake in the various departments in the typical area of responsibility of a CFO.

The questionnaire was pre-tested by a small group of academics and three CFOs. This process resulted in minor changes to some of the wordings and the presentation of the questionnaire. To improve construct validity the questionnaire contains items already used in previous studies whenever possible.

\subsection{Variable measurement}

Data for seven of the nine main variables were collected by our survey instrument: Data frequency, interactive data usage, autonomy restriction, short-term finance 
focus, crisis impact, sustainable relations with employees and sustainable relations with external stakeholders. Each of these constructs was operationalized through 3 to 5 items. As a response format, each item was measured on a seven-point Likert scale anchored by $1=$ does not apply at all and $7=$ applies fully. Data for the remaining two variables industry and size were obtained from the AMADEUS database.

Items used were adapted from Simons (1995), Henri (2006) and Widener (2007) as well as from Smart and Vertinsky (1984). In their seminal work on corporate responses to crises, Smart and Vertinsky (1984) derived several crisis-coping strategies through a content analysis on seventy corporate case studies that described the actions of various firms facing crises. The remainder of the items was specially developed to reflect the specific contingencies CFOs face in economic crisis situations. A description of variables employed is provided below. The relevant variables for this study were measured using multiple items that represent latent variables. Reliability and validity were assessed using factor analysis and Cronbach $\alpha$. Manifest indicators for each latent variable were created by averaging the items for each scale. Each of the variables is discussed in turn.

\subsubsection{Crisis impact (CI)}

In order to measure the crisis impact companies have to deal with, we purposedeveloped a 5-item construct (revenue decline, margin decline, cash-flow decline, decline in orders, excess capacities). The survey questionnaire thus contained five statements, both financial and non-financial in nature (revenues decline, margin decline, cash-flow decline, decline in orders, excess capacities due to the crisis). These items were selected in order to incorporate leading, lagging and coincident indicators for a crisis-related pressure on organizations. These five items together measure the severity of crisis impact companies face. Factor analysis reveals that these five items load on the same factor. Additionally, the construct crisis impact was correlated with a single-item measure that measures the extent to which companies are negatively affected by the current economic crisis. The analysis yielded a correlation coefficient close to 1 (0.849), which again underlines our contention that the measure we have constructed is an appropriate proxy (Cronbach $\alpha=0.902$ ).

In our study we employ a set of variables that describe the use of control mechanisms relying on previous literature showing the particular relevance of these control mechanisms in crisis situations. We assume that the underlying control mechanisms exist in all companies; however, firms in our sample differ in the use of these controls.

\subsubsection{Data frequency $(D F)$}

Relying on specifications of measures by Smart and Vertinsky (1977) and Ritchie (2004), we employ four items referring to the shortening of reporting intervals, the faster and more frequent reporting of deviations from pre-defined target values, the shortening of the operational planning horizon and the more frequent analysis of 
the economic situation of customers to discover dangerous developments in the client's business as soon as possible (Cronbach $\alpha=0.773$ ).

\subsubsection{Interactive data usage (IDU)}

Building on Ezzamel and Bourn (1990) and Smart and Vertinsky (1977), we used items that measure the interaction going on among employees during the decision process. The three items used concern increased discussions of deviations from preset performance targets, the coordination among the different departments that are involved in the working capital process and the questioning and a more critical discussion of premises for projects with the employees in charge (Cronbach $\alpha=0.714)$.

\subsubsection{Autonomy restriction $(A R)$}

In line with Hermann (1963), we used items that measure the degree of autonomy restriction employees are confronted with. The three items used cover the pressure on employees with bad performance, the increased use of a top-down leadership style through target setting and the definition of clear guidelines and the use of codes of conduct for employees with regard to risk-taking behavior (Cronbach $\alpha=0.772$ ).

\subsubsection{Short-term finance focus (STFF)}

Our variable measures draw on Gilson and Vetsuypens (1993), Ittner et al. (1997), Müller (1985) and Rhodes and Stelter (2009). The five items used comprise a stronger orientation towards liquidity and cash-flow measures relevant for employee target setting, cutting cost budgets across the company, the use of restructuring initiatives to increase the process efficiency and to lower costs, cutting R\&D expenditures and cutting investment budgets (Cronbach $\alpha=0.718$ ).

Due to the lack of appropriate measures in the existing literature, our measures of stakeholder variables have been specially developed for the purpose.

\subsubsection{Sustainable relations with employees (SRWEMPLOY)}

The extent to which companies engage in sustainable relations with their employees was measured using three items: the introduction of short-time work, increased cooperation with union representatives to boost efficiency and the retention of as many employees as possible through socially acceptable measures (Cronbach $\alpha=0.738)$.

\subsubsection{Sustainable relations with external stakeholders (SRWESTAKE)}

The extent to which companies invest in sustainable relations with external stakeholders was measured using five items: more intense and more active communication with investors, paying attention not to harm the relationship with 
important business partners through short-term optimization measures, acknowledging and making allowances to business partners that are severely hit by the economic crisis, and intensifying key account management to foster mutual trust and an increased cooperation with special interest groups (labor unions, Austrian chamber of commerce, etc.) (Cronbach $\alpha=0.698$ ).

Our study also includes two control variables that have been operationalized building on measures from previous research.

\subsubsection{Organizational size (SIZE)}

In accordance with previous contingency-based research, organizational size was included (e.g. Chapman 1998; Chenhall 2003). Two different measures for size have been employed, namely the number of employees and turnover. According to Libby and Waterhouse (1996), size has been measured most often in the past as the natural logarithm of the number of employees of the company. Hence, in this study size is measured accordingly.

\subsubsection{Industry (IND)}

Industry affiliation is included as a second control variable in this study, as was the case in most previous contingency studies (e.g. Chapman 1998; Chenhall 2003). Controlling for industry effects seems to be especially important since the current economic crisis seems to have different effects on companies with regards to timing and severity in the various sectors. We distinguished between trade, production, service and other industries, while financial institutions were excluded from the target population.

\section{Results}

\subsection{Descriptive statistics}

Table 2 depicts the descriptive statistics for the main variables. The values for the Cronbach $\alpha$ for the main variables are all above the recommended level of 0.60 (Nunnally 1967). The factor loadings for all variables are all above the recommended level of 0.40 (Onsi 1973).

For the purpose of enhancing internal validity, late response bias was tested by halving the samples and running ANOVA to test for differences in means in selected questionnaire items (see Table 3).

Moreover, non-response bias was assessed performing ANOVA to test for differences in demographic characteristics between participants and non-participants in terms of organizational size (number of employees and revenue). In both cases, no significant differences were found.

Table 4 shows the results for the correlation analysis for the variables used in this paper. 
Table 2 Descriptive statistics—overview of main variables $(n=204)$

\begin{tabular}{llllllll}
\hline Variable & Variable description & $\begin{array}{l}\text { No. of } \\
\text { items }\end{array}$ & $\begin{array}{l}\text { Cronbach } \\
\alpha\end{array}$ & Mean & SD & $\begin{array}{l}\text { Theoretical } \\
\text { range }\end{array}$ & $\begin{array}{l}\text { Actual } \\
\text { range }\end{array}$ \\
\hline 1. CI & Crisis impact & 5 & 0.902 & 4.156 & 1.524 & $1.00-7.00$ & $1.00-7.00$ \\
2. DF & Data frequency & 4 & 0.773 & 3.868 & 1.588 & $1.00-7.00$ & $1.00-7.00$ \\
3. IDU & Interactive data usage & 3 & 0.714 & 4.768 & 1.449 & $1.00-7.00$ & $1.00-7.00$ \\
4. AR & Autonomy restriction & 3 & 0.772 & 4.672 & 1.414 & $1.00-7.00$ & $1.00-7.00$ \\
5. STFF & $\begin{array}{l}\text { Short-term finance } \\
\text { focus }\end{array}$ & 5 & 0.718 & 4.239 & 1.306 & $1.00-7.00$ & $1.00-7.00$ \\
6. SRWEMPLOY & $\begin{array}{c}\text { Sustainable relations } \\
\text { with employees }\end{array}$ & 3 & 0.738 & 3.507 & 1.786 & $1.00-7.00$ & $1.00-7.00$ \\
7. SRWESTAKE & $\begin{array}{c}\text { Sustainable relations } \\
\text { with external } \\
\text { stakeholders }\end{array}$ & 5 & 0.698 & 4.203 & 1.148 & $1.00-7.00$ & $1.00-6.40$ \\
& & & & & & & \\
\hline
\end{tabular}

Table 3 ANOVA-results of tests for early-late response bias

\begin{tabular}{lll}
\hline Non-response bias & & \\
\hline Variable & $\mathrm{F}$ & $\mathrm{P}$ \\
\hline 1. CI & 0.083 & 0.774 \\
2. DF & 0.799 & 0.374 \\
3. IDU & 0.063 & 0.802 \\
4. AR & 1.123 & 0.292 \\
5. STFF & 1.209 & 0.274 \\
6. SRWEMPLOY & 1.501 & 0.224 \\
7. SRWESTAKE & 0.518 & 0.473 \\
8. SIZE & 0.030 & 0.863 \\
\hline
\end{tabular}

\subsection{Regression model and results for hypotheses $1 \mathrm{a}-\mathrm{d}$}

Since a selection-fit approach to contingency-based MCS research is followed in this paper, regression analysis is employed to test the propositions (Hoque 2006). Using the OLS-regression technique allows establishing that a set of independent variables explains a proportion of the variance in a dependent variable at a significant level (through a significance test of $\mathrm{R}^{2}$ ).

Multiple regression analysis is run for the various controls and sustainable relations with both, employees and external stakeholders using crisis impact, organizational size and industry affiliation as independent variables in each regression.

\section{Use of management controls}

$$
=f(\text { crisis impact, organizational size, industry affiliation })
$$


Table 4 Correlation matrix $(n=204)$

\begin{tabular}{|c|c|c|c|c|c|c|c|c|c|}
\hline Variable & & 1 & 2 & 3 & 4 & 5 & 6 & 7 & 8 \\
\hline \multirow[t]{2}{*}{ 1. CI } & & 1.000 & & & & & & & \\
\hline & Prob $(\mathrm{T})$ & & & & & & & & \\
\hline \multirow[t]{2}{*}{ 2. DF } & & $0.405^{* * *}$ & 1.000 & & & & & & \\
\hline & Prob $(\mathrm{T})$ & 0.000 & & & & & & & \\
\hline \multirow[t]{2}{*}{ 3. IDU } & & $0.318 * * *$ & $0.599 * * *$ & 1.000 & & & & & \\
\hline & Prob $(\mathrm{T})$ & 0.000 & 0.000 & & & & & & \\
\hline \multirow[t]{2}{*}{ 4. STFF } & & $0.533 * * *$ & $0.464 * * *$ & $0.576^{* * *}$ & 1.000 & & & & \\
\hline & Prob $(\mathrm{T})$ & 0.000 & 0.000 & 0.000 & & & & & \\
\hline \multirow[t]{2}{*}{ 5. AR } & & $0.242 * * *$ & $0.493 * * *$ & $0.626^{* * * *}$ & $0.580 * * *$ & 1.000 & & & \\
\hline & Prob $(\mathrm{T})$ & 0.000 & 0.000 & 0.000 & 0.000 & & & & \\
\hline \multirow[t]{3}{*}{ 6. SRWEMPLOY } & & $0.571 * * *$ & $0.424 * * *$ & $0.451^{* * *} *$ & $0.570^{* * *}$ & $0.383 * * *$ & 1.000 & & \\
\hline & Prob $(\mathrm{T})$ & 0.000 & 0.000 & 0.000 & 0.000 & 0.000 & & & \\
\hline & & $0.313 * * *$ & $0.473 * * *$ & $0.470^{* * * *}$ & $0.381 * * *$ & $0.420 * * *$ & $0.428 * * *$ & 1.000 & \\
\hline \multirow[t]{2}{*}{ 7. SRWESTAKE } & Prob $(\mathrm{T})$ & 0.000 & 0.000 & 0.000 & 0.000 & 0.000 & 0.000 & & \\
\hline & & $0.204 * * *$ & 0.033 & $0.232 * * *$ & $0.217^{* * * *}$ & $0.155 * *$ & $0.256 * *$ & 0.105 & 1.000 \\
\hline 8. SIZE & Prob $(\mathrm{T})$ & 0.003 & 0.642 & 0.001 & 0.002 & 0.027 & 0.000 & 0.136 & \\
\hline
\end{tabular}

$* 10 \%$ confidence level. $* * 5 \%$ confidence level. $* * * 1 \%$ confidence level

\section{Sustainable relations with stakeholders \\ $=f($ crisis impact, organizational size, industry affiliation $)$}

Hypotheses 1a-d and 2 were tested using OLS regression analysis. The results indicate that crisis impact drives the use of controls (see Table 5). The more companies face negative crisis effects, the more intensively they make use of the various controls.

Hypothesis 1a predicted a positive relationship between crisis impact and the shortening of reporting cycles. This prediction is supported by the analysis of our data. The results show a positive and highly significant effect of crisis impact on the emphasis placed on data frequency.

The results of regression analysis are also in line with the direction of the effect of crisis impact on the interactive use of control-relevant information predicted in hypothesis $1 \mathrm{~b}$. The regression coefficient is positive and highly significant, thus underlining the prediction that companies facing more negative crisis effects place more emphasis on the interactive use of data. Additionally, organizational size yields a positive and highly significant effect on interactive data usage.

In Hypothesis 1c, a positive relation between autonomy restriction and crisis impact is expected. Again, data analysis confirms our prediction by revealing a positive and highly significant regression coefficient. As companies face more crisis pressure, they increasingly "tighten their strings". What is more, controlling for organizational size yields a weakly positive effect at the $10 \%$ level.

The results also confirm hypothesis $1 \mathrm{~d}$, which predicts a positive effect of crisis impact on the focus on liquidity and cost cutting. The more severely companies are 
Table 5 Results of regression analysis $(n=204)$

\begin{tabular}{|c|c|c|c|c|c|c|c|c|}
\hline $\begin{array}{l}\text { Dependent } \\
\text { variable }\end{array}$ & & DF & IDU & STFF & $\mathrm{AR}$ & SRWEMPLOY & SRWESTAKE & $\begin{array}{l}\text { Variance } \\
\text { inflation } \\
\text { factor } \\
\text { (VIF) }\end{array}$ \\
\hline \multirow[t]{2}{*}{ Intercept } & & $2.310 * * *$ & $2.641 * * *$ & $1.974 * * *$ & $2.963 * * *$ & 0.890 & $2.941 * * *$ & \\
\hline & Prob $(\mathrm{T})$ & 0.000 & 0.000 & 0.000 & 0.000 & 0.125 & 0.000 & \\
\hline \multirow[t]{2}{*}{ CI } & & $0.421 * * *$ & $0.269 * * *$ & $0.491 * * *$ & $0.234 * * *$ & 0.460 *** & $0.296^{* * *}$ & 1.188 \\
\hline & Prob $(\mathrm{T})$ & 0.000 & 0.000 & 0.000 & 0.002 & 0.000 & 0.000 & \\
\hline \multirow[t]{2}{*}{ SIZE } & & -0.037 & $0.187 * * *$ & $0.107 *$ & $0.123^{*}$ & $0.114 *$ & 0.042 & 1.142 \\
\hline & Prob $(\mathrm{T})$ & 0.589 & 0.009 & 0.092 & 0.094 & 0.054 & 0.557 & \\
\hline \multirow[t]{2}{*}{ IND Trade } & & 0.027 & -0.021 & -0.054 & 0.050 & $-0.239 * * *$ & -0.021 & 1.484 \\
\hline & Prob $(\mathrm{T})$ & 0.730 & 0.798 & 0.459 & 0.549 & 0.000 & 0.794 & \\
\hline \multirow[t]{2}{*}{ Services } & & -0.043 & -0.102 & -0.051 & 0.000 & $-0.185^{* * *}$ & -0.032 & 1.201 \\
\hline & Prob $(\mathrm{T})$ & 0.545 & 0.159 & 0.435 & 0.999 & 0.002 & 0.663 & \\
\hline \multirow[t]{2}{*}{ Others } & & -0.002 & -0.087 & -0.059 & -0.014 & $-0.146^{* *}$ & -0.067 & 1.128 \\
\hline & Prob $(\mathrm{T})$ & 0.976 & 0.213 & 0.347 & 0.846 & 0.013 & 0.350 & \\
\hline $\mathrm{R}^{2}$ & & $17 \%$ & $14.4 \%$ & $30.1 \%$ & $7.3 \%$ & $40.1 \%$ & $10.4 \%$ & \\
\hline Adj. $\mathrm{R}^{2}$ & & $14.9 \%$ & $12.2 \%$ & $28.4 \%$ & $4.9 \%$ & $38.5 \%$ & $8.2 \%$ & \\
\hline $\mathrm{N}$ & & 204 & 204 & 204 & 204 & 204 & 204 & \\
\hline
\end{tabular}

As a rule of thumb, the variance inflation factor (VIF) should not exceed five for multicollinearity not to pose a problem (Menard 1995). Production industry serves as baseline for other industry dummy variables

$* 10 \%$ confidence level. ** $5 \%$ confidence level. $* * * 1 \%$ confidence level

affected by the crisis the more they rely on a short-term financially driven orientation to ensure their short-term survival. Moreover, controlling for organizational size shows a weak positive effect at the $10 \%$ level.

\subsection{Results for hypotheses 2}

OLS regression analysis yields a highly significant and positive effect of crisis impact on sustainable relations with both employees and external stakeholders.

With regards to external stakeholders, the results show that the more severely companies are affected by the current economic crisis, the more they invest in sustainable relations with external stakeholders. These results are not affected by organizational size and industry affiliation.

Concerning sustainable relations with employees, our results indicate that the more severe the crisis impact, the more emphasis organizations place on sustainable relations with their employees. Moreover, organizational size has a weakly positive effect on sustainable relations with employees at the $10 \%$ level. Controlling for industry affiliation, our results show that companies in the trade, service and other industries place less emphasis on sustainable relations with employees than firms in the production sector.

Moreover, the predictor variables were tested for multicollinearity issues. Since the variance inflation factor (VIF) did not exceed (1.484), multicollinearity does not seem to pose a threat to the validity of our results (Menard 1995). 
Looking at the explanatory power of both stakeholder models, it is obvious that the model for sustainable relations with employees is more strongly supported by our data (adjusted $\mathrm{R}^{2}=38.5 \%$ ) than the model for relations with external stakeholders (adjusted $\mathrm{R}^{2}=8.2 \%$ ). The fact that negative crisis effects explain more of the variance within the internal stakeholder model than is the case for the external stakeholder model might be due to the fact that sustainable relations with external stakeholders may be determined by a broader set of factors.

\subsection{Results for association between short-term finance focus and stakeholder management}

In order to explore the nature of this relationship in highly crisis-affected organizations, we used a two-step approach. In the first stage, we use a two-step cluster analysis to find clusters that differ with respect to the mean crisis impact. In doing so, the analysis reveals two clusters. The first cluster derived is characterized by a high crisis impact (5.53). The second cluster includes companies only marginally affected by the recent economic crisis (2.96).

In step two of our analysis, we run a correlation analysis for the emphasis placed on sustainable relations with stakeholders and the short-term focus on liquidity and cost-cutting for the highly crisis-impacted cluster in order to shed light on the nature of the relationship between these three variables.

The correlation analysis (Table 6) yields consistently positive correlation coefficients which are all highly significant. These results provide initial evidence that there seems to be no contradiction between a company's focus on a short-term crisis-related cost and liquidity management and its stakeholder approach in severe crisis situations. This indicates that even severely crisis-impacted companies are extremely cautious not to harm their relationships with stakeholders while taking necessary crisis response measures.

With regards to sustainable employee relationship management, our correlation results indicate that companies that are highly affected by the recent crisis $(n=95)$ seem to be able to reconcile sustainable relations with their employees while tightening their short-term finance focus $(\rho=0.572 * * *)$.

Concerning a sustainable orientation towards external stakeholders, our correlation results are highly significant and positive. Short-term finance focus $\left(\rho=0.316^{* * *}\right)$ shows a strong association with the emphasis placed on a sustainable orientation towards external stakeholders.

These findings seem to demonstrate that highly crisis-affected firms do follow a sustainable stakeholder-relations approach mostly independently of their focus on liquidity and cost cutting measures.

\section{Discussion and conclusions}

Our study provides evidence on the impact of the recent economic crisis on management control systems and on stakeholder management activities. Using survey data from 204 major Austrian corporations, our empirical findings indicate 
Table 6 Correlation matrix $(n=95)$

\begin{tabular}{lllll}
\hline Variable & & 1 & 2 & 3 \\
\hline 1. STFF & & 1.000 & & \\
2. SRWEMPLOY & Prob (T) & & & \\
& & $0.572^{* * * *}$ & 1.000 & 1.000 \\
3. SRWESTAKE & Prob (T) & 0.000 & & \\
\hline
\end{tabular}

$* 10 \%$ confidence level. $* * 5 \%$ confidence level. $* * * 1 \%$ confidence level

that firms acknowledge the need to adjust their management control systems to the new challenges arising from the occurrence of economic crises. Not unexpectedly, firms that are put under severe pressure by an economic crisis need to focus on financials to support and monitor cash management as well as on cost-cutting activities and such firms seek for more up-to-date information by shortening their reporting cycles. Interestingly, financial leaders also seem to adjust their leadership style in exerting control towards employees during crisis situations. On the one hand firms tighten the reins and restrict the autonomy of their employees; on the other hand they encourage a more interactive use of control-relevant data, intensifying discussion with and among employees and challenging the assumptions made.

As suggested by stakeholder theory, firms acknowledge the need to actively manage their stakeholder relationships in times of pressure to cut costs and preserve liquidity. Obviously, finance executives do not see an immanent contradiction between short-term control needs and stakeholder-related activities to enable longterm stability in times of crisis. Our theoretical deliberations and our empirical results not only contribute to the literature on management in times of external crisis but also are an important step towards a more integrated view of management accounting and stakeholder management.

However, several limitations of our study need to be considered. First, the use of a limited number of independent variables in the OLS regressions leads to the problem of causality and the omitted variable problem. Second, the survey-based instrument is of course subject to the general limitations of this type of research (Birnberg et al. 1990). The single respondent approach used and the fact that CFO perceptions are measured needs to be considered when interpreting our results. Moreover, our study does not include the financial sector, which has played a very specific role during the recent economic crisis.

With respect to future research, considering performance implications of certain management control and stakeholder management policies could yield deeper insight. Also the inclusion of case-based evidence seems quite promising. While firms tend to complement the increased focus on short-term financials during a crisis with long-term stakeholder activities, there are firms in our sample that do not. It might be interesting to analyze the reasons why some firms obviously see a contradiction between short-term and long-term needs while others do not. 
Acknowledgments The authors gratefully acknowledge the support provided by the ÖCI (Österreichisches Controller-Institut) and the great commitment of the students of the spring term 2009 IfU project seminar. Moreover, the helpful comments provided by the EURAM conference participants as well as the feedback of the anonymous reviewers are highly appreciated. Finally, the authors are deeply grateful to all participating Austrian CFOs for taking their time to complete the survey despite the difficult economic environment prevailing.

\section{References}

Atkinson AA, Waterhouse JH, Wells RB (1997) A stakeholder approach to strategic performance measurement. Sloan Manag Rev 38:25-37

Birnberg J, Shields M, Young S (1990) The case for multiple research methods in empirical management accounting research (with an illustration from budget setting). J Manag Acc Res 2:33-66

Chapman CS (1998) Accountants in organisational networks. Acc Organ Soc 23:737-766

Chenhall RH (2003) Management control systems design within its organizational context: findings from contingency-based research and directions for the future. Acc Organ Soc 28:127-168

Cornell B, Shapiro AC (1987) Corporate stakeholders and corporate finance. Financ Manag 16:5-14

Davila A, Foster G et al (2009) Reasons for management control systems adoption: insights from product development systems choice by early-stage entrepreneurial companies. Acc Organ Soc 34:322-347

Ezzamel M, Bourn M (1990) The roles of accounting information systems in an organization experiencing financial crisis. Acc Organ Soc 15:399-424

Ferreira A, Otley D (2010) Design and use of management control systems: an analysis of the interaction between design misfit and intensity of use. Working paper

Freeman RE, Gilbert DR (1987) Managing stakeholder relationships. In: Sethi SP, Falbe CM (eds) Business and society: dimensions of conflict and cooperation. Lexington Books, Lexington, pp 397-423

Galbraith JR (1973) Designing complex organizations. Addison-Wesley, Reading

Gilson SC, Vetsuypens MR (1993) CEO compensation in financially distressed firms: an empirical analysis. J Financ 48:425-458

Henri JF (2006) Management control systems and strategy: a resource-based perspective. Acc Organ Soc 31:529-558

Hermann CF (1963) Some consequences of crisis which limit the viability of organizations. Adm Sci Q 8:61-82

Hopwood A (2009) The economic crisis and accounting: implications for the research community. Acc Organ Soc 34:797-802

Hoque Z (2006) Methodological issues in accounting research: theories, methods and issues. Spiramus Press, London

Ittner CD, Larcker DF et al (1997) The choice of performance measures in annual bonus contracts. Acc Rev 72:231-255

Jones TM (1995) Instrumental stakeholder theory: a synthesis of ethics and economics. Acad Manag Rev 20:404-437

Kaplan R, Norton D (1996) The balanced scorecard: translating strategy into action. Harvard Business School Press, Boston

Libby T, Waterhouse JH (1996) Predicting change in management accounting systems. J Manag Acc Syst $8: 137-150$

Malmi T, Brown DA (2008) Management control systems as a package: opportunities, challenges and research directions. Manag Acc Res 19:287-300

Malmi T, Granlund M (2009) In search of management accounting theory. Eur Acc Rev 18:597-620

Menard S (1995) Applied logistic regression analysis. Sage University Series, Thousand Oaks

Merchant KA (1990) The effects of financial controls on data manipulation and management myopia. Acc Organ Soc 15:297-313

Merchant KA, Van der Stede WA (2007) Management control systems, 2nd edn. Prentice Hall, Pearson Education Limited, England

Mitchell RK, Agle BR, Wood DJ (1997) Toward a theory of stakeholder identification and salience: defining the principle of who and what really counts. Acad Manag Rev 22:853-886

Müller R (1985) Corporate crisis management. Long Range Plan 18:38-48 
Nixon WAJ, Burns J (2005) Management control in the 21st century. Manag Acc Res 16:260-268

Nunnally JC (1967) Psychometric theory. McGraw Hill, New York

Onsi M (1973) Factor analysis of behavioural variables affecting budgetary slack. Acc Rev 48:535-548

Pearson CM, Clair JA (1998) Reframing crisis management. Acad Manag Rev 23:59-76

Pearson CM, Mitroff II (1993) From Crisis prone to crisis prepared: a framework for crisis management. Acad Manag Exec 7:48-59

Perrini F, Tencati A (2006) Sustainability and stakeholder management: the need for new corporate performance evaluation and reporting systems. Bus Strategy Environ 15:296-308

Rhodes D, Stelter D (2009) Seize advantage in a downturn. Harv Bus Rev 87:50-58

Ritchie BW (2004) Chaos, crises and disasters: a strategic approach to crisis management in the tourism industry. Tourism Manag 25:669-683

Simons R (1995) Levers of control, how managers use innovative control systems to drive strategic renewal. Harvard Business School Press, Boston

Smart C, Vertinsky I (1977) Designs for crisis decision units. Adm Sci Q 22:640-657

Smart C, Vertinsky I (1984) Strategy and the environment: a study of corporate responses to crises. Strateg Manag J 5:199-213

Speckbacher G, Wentges P (2010) A note on stakeholder theory and risk: implications for corporate cash holdings and dividend policy. Front in Finance Econ 6:51-72

Speckbacher G, Bischof J, Pfeiffer T (2003) A descriptive analysis on the implementation of balanced scorecards in german-speaking countries. Manag Acc Res 14:361-388

Sundin H, Granlund M, Brown DA (2010) Balancing multiple competing objectives with a balanced scorecard. Eur Acc Rev 19:203-246

Ulmer RR (2001) Effective crisis management through established stakeholder relationships: malden mills as a case study. Manag Commun Q 14:590-615

Widener S (2007) An empirical analysis of the levers of control framework. Acc Organ Soc 32:57-788 